IV Congreso Internacional Estética y Política Poéticas del desacuerdo para una democracia plural

\title{
El sentido de la democracia en la filosofía estética de Jean-Luc Nancy
}

\section{Paula Sánchez}

Universidad Complutense de Madrid, pasanc05@ucm.es

\begin{abstract}
In the framework of politics and aesthetics, Jean-Luc Nancy appears as one of the thinkers who has been most interested in these issues. This paper offers a reading of some of the fundamental notions of his thinking, highlighting the role that the ontology of "being-with" has in relation to the notion of democracy. It is thus intended to show a line of thought that leaves room for the instability that the word "democracy" faces today, emphasizing the fragility of an ontology that, on the other hand, responds lucidly to the way of being of the entities that, like the human being, live in relation to each other.
\end{abstract}

Keywords: being-with, democracy, singular-plural, together, relational ontology

\begin{abstract}
Resumen
En el marco de la política y la estética, Jean-Luc Nancy aparece como uno de los pensadores que más se ha interesado por esas cuestiones. En el presente escrito se ofrece una lectura de algunas de las nociones fundamentales de su pensamiento, relsaltando el papel que la ontología del "ser-con" tiene en relación a la noción de democracia. Se pretende así mostrar una línea de pensamiento que deja lugar para la inestabilidad a la que hoy día se enfrenta la palabra "democracia”, poniendo el acento en la fragilidad de una ontología que, por otra parte, responde con lucidez al modo de ser de los entes que, como el ser humano, vivimos en relación unos con otros.
\end{abstract}

Palabras clave: ser-con, democracia, singular-plural, juntos, ontología relacional. 


\section{Introducción}

Jean-Luc Nancy se ha consagrado como uno de los mayores pensadores en el ámbito de la estética y de la política, su numerosa producción filosófica abarca temas tan diversos como la libertad, el mundo, la comunidad, el arte y el ser. En esta ocasión nos proponemos dibujar un mapa conceptual que se haga cargo del pensamiento político del autor y de su fundamentación ontológica y estética. Con este propósito la noción principal que se va a examinar es la de democracia, palabra antigua y manida como no hay otra, también admirada, reclamada y criticada por unos y otros. La propuesta no versará tanto sobre la respuesta que Nancy pueda dar o no a los problemas políticos más actuales y fácticos, sino que se tratará de esbozar las líneas argumentales que, en el pensamiento del autor francés, llevan de una ontología relacional, fundamentada en el mit-sein heideggeriano, a un planteamiento eminentemente estético de la noción de democracia.

Teniendo en cuenta lo precedente habrá que advertir que aquí la palabra estética está siendo usada en su sentido más amplio y etimológico, es decir, en lo que atañe a la sensibilidad corporal; de esta manera el pensamiento de Nancy está teñido de estética en todos sus ámbitos y niveles.

Por otro lado, aunque íntimamente ligado a las observaciones anteriores, la palabra sentido aparecerá recurrentemente a lo largo de este escrito. Se trata de una de las inquietudes más repetidas del autor y el trabajo que opera con ella resulta innovador y una clara muestra de la preocupación por el mundo que emerge tras el cambio de paradigma de principios del siglo XX. El sentido ya no obedece a la clásica interpretación de la "verdad" absoluta e inmutable que de alguna manera se oculta detrás de los entes del mundo y les de su razón de ser. Por el contrario, para Nancy el sentido se comprende a partir de la relación, el movimiento y la circulación de los cuerpos, siendo aquello que los une y los separa, que surge en cada roce y cada contacto, no pudiendo, por ello mismo, ser reducido a una significación última, sino siempre en constante fuga.

\section{Desarrollo}

\subsection{Ser-con}

La ontología de Nancy puede definirse como una ontología relacional donde el elemento central es la partícula "con", esta partícula conlleva la necesidad de relación de varios términos. Lo característico es que esta partícula se instaura en el núcleo del ser (del venir a ser), lo que implica una noción de origen fragmentada, plural y equívoca. El "con" se inserta así en el origen del sentido y de cada particularidad, de ahí la insistencia de Nancy en que el ser es singular plural. Esto es así porque la manera de ser del ser (de nuevo: del sentido) es siendo en la circulación de unos con otros. Con estas breves indicaciones ya han salido a escena los términos más importantes: singular-plural, unos-otros. Estos términos singular-plurales (que no pueden existir por separado) conforman el esquema del pensamiento ontológico de Nancy y revelan los modos de exponer la com-partición. En una de las obras más interesantes para esta cuestión, que no por casualidad se titula Ser singular plural, leemos lo siguiente: “el ser no puede ser más que siendo-los-unos-con-los-otros, circulando en el con de esta co-existencia singularmente plural” (Nancy, 2006).

La singularidad no es la individualidad, la singularidad emerge y se hace concreta en la partición que divide y, a la vez, en tanto que divide, comunica un cuerpo con otro, una voz con otra, una escritura con otra. La singularidad "está asociada al éxtasis: no podría decirse con propiedad que el ser singular es el sujeto del éxtasis, porque éste no tiene "sujeto", sino que debe decirse que el éxtasis (la comunidad) le acaece al ser singular" (Nancy, 2001). Parecería contradictorio si seguimos pensando el sujeto como un átomo entre otros, sin embargo Nancy ya está pensando desde una ontología del ser-en-común, desde la cual los singulares son en tanto que partición y ruptura interna, porque no hay nada interno más que el abrirse hacia el exterior, hacia los otros que no son otros más que estando ya en nuestro interior. El ser singular se aleja también de la fusión de la comunión y de la inmanencia en tanto que no supone un fondo común al que todos perteneceríamos, el ser-en-común es la existencia de cada uno ${ }^{1}$.

\footnotetext{
1“Somos los-unos-con-los-otros, sí, pero de ello no puede inferirse una unidad de todos los seres, una fusión, una comunidad identitaria. En el nosotros se aloja la alteridad, el otro, que impide la absorción de las partes en una totalidad y preserva las diferencias que delimitan las singularidades" (Massó Castilla, 2014)
} 
La pluralidad que implica toda singularidad supone, además de una no identidad y no unidad en el origen, que en cada uno, en cada identidad está ya el otro. Esta relación de la alteridad que habita en la identidad es posible porque la existencia es exposición, exposición al otro que de esta manera nos procura existencia (ser, sentido). Ya que, una vez más, el ser es relación de sentido en la que hace falta el uno y el otro a la vez, de manera co-originaria. Por eso, puede decir Nancy que comparecer es venir juntos al mundo, y no hay otra manera de ser, porque el ser mismo consiste en la comparecencia de unos y otros:

Comparecemos: venimos juntos al mundo. No se trata de que haya una producción simultánea de muchas entidades distintas (como cuando vamos "juntos" al cine), sino de que no hay venida al mundo que no sea radicalmente común. Lo "común" mismo. Venir al mundo = ser-en-común. (Nancy, 2014)

La relación en la cual se opera este "juntos" es la exposición. La exposición al otro, a la alteridad es la manera de estar juntos y de integrar la otredad en la mismidad. Exposición como apertura originaria de ser, como manera de comparecer los unos ante los otros, pero a la vez los unos en (dentro, en las entrañas) los otros. Existir consiste en ser expuesto, es mediante la exposición como somos-con:

Expuesto, por tanto: pero no es la puesta ante la vista de lo que primero estuvo oculto, encerrado. Aquí, la exposición es el ser mismo (léase: existir). O todavía mejor: si el ser, en cuanto sujeto, tiene por esencia la autoposición, aquí la autoposición es ella misma, en tanto que tal, por esencia y por estructura, la exposición. Auto $=e s=$ cuerpo. El cuerpo es el ser-expuesto del ser. (Nancy, 2010)

De esta manera, a través de la exposición que se deriva de la ontología del ser-con, llegamos al cuerpo como lugar de exposición. Más adelante veremos que Nancy juega con la palabra expeausition, para indicar cómo la piel [la peau] juega el papel de expositora. Pero la noción de exposición tiene aún una característica importante: impide la apropiación, el estar expuestos supone que lo otro está ya, desde siempre en mí, en la mismidad o en la identidad, que al estar contaminada desde dentro por la alteridad ya no es apropiable. La alteridad que se encuentra en la mismidad es precisamente la fractura (plural) de cualquier mismidad. El ser es singular-plural, somos los-unos-con-los-otros, existimos expuestos; todas estas determinaciones ontológicas remiten a la ruptura con la idea de propiedad de la identidad, que comienza tradicionalmente con la propiedad del cuerpo: hoc est enim corpum meum.

\subsection{Democracia}

Si seguimos indagando en la partícula "con" advertimos en los trabajos de Nancy que "la mera yuxtaposición de objetos tiene ya la potencia de hacer sentido. No de producir significaciones (que no dejan de ser débiles, como la idea de comer los espárragos), sino sentido, una apertura de sentido, porque el sentido nunca es otra cosa que una remisión de un lugar a otro, de presencia en presencia" (Nancy, 2011).

Esta cita proviene de un artículo que, no por casualidad, lleva por título Ser- con y democracia. El atento análisis de este pequeño escrito será fundamental para alcanzar la comprensión de la argumentación que lleva al autor del régimen ontológico al político.

El pensamiento político de Nancy puede rastrearse en la mayoría de sus obras, sin embargo, en vista a la concreción y la síntesis, abarcaremos algunas de las más representativas. En el artículo que se acaba de señalar aparece la siguiente definición de democracia:

La democracia en tanto que poder del pueblo significa el poder de todos en tanto que están juntos, es decir, los unos con los otros. No es el poder de todos como poder de cualquiera, ni de la masa entera sobre una simple yuxtaposición de individuos dispersos. Es un poder que presupone no la dispersión que se mantiene bajo la autoridad de un principio o de una fuerza de reunión, sino la dis-posición de la yuxta-posición. Es decir, a la vez una disposición que no comporta por sí misma ninguna jerarquía ni subordinación, y una yuxtaposición que se entiende existencialmente como un reparto del sentido de ser. (Nancy, 2011)

De esta manera la democracia designa antes una forma de estar juntos que una forma de poder político. En otras palabras, la verdadera democracia (a continuación se verá qué ocurre con la democracia que podríamos decir no verdadera o malobrada) se instala en el centro mismo de la ontología relacional, en lugar de situarse en un nivel más superficial o fáctico, el autor la sitúa en el régimen de la ontología, y por consiguiente, en el régimen del ser, de lo que es. 
Es esta diferenciación de regímenes o niveles donde se encuentra el problema de la democracia. El haber querido situarla en un nivel que no es el suyo ha hecho que no los resultados políticos y sociales no hayan satisfecho las expectativas que en la idea de democracia habían sido puestas.

Destacando el arrojo que tiene haber titulado a su libro La verdad de la democracia, aportamos aquí algunas líneas de esta obra, en la que Jean-Luc Nancy se propone analizar el estatuto que tiene hoy día, y especialmente desde los acontecimientos de Mayo del 68, la noción de democracia. Se puede observar que aquí, la definición de democracia vuelve a estar íntimamente ligada con la ontología del ser-con, que no deja lugar para una jerarquía o autoridad:

Si la democracia tiene un sentido, debe ser el de no disponer de ninguna autoridad identificable a partir de un lugar y un impulso diferentes de los de un deseo - una voluntad, una expectativa, un pensamiento - en el cual se exprese y se reconozca una verdadera posibilidad de ser todos juntos, todos y cada uno de nosotros. (Nancy, 2009)

Más adelante, el autor se propone indagar en las razones de la decadencia, por así decirlo, de la idea de democracia. Encuentra así el mayor problema de la democracia en la idea de la equivalencia que ha predominado, a su parecer, desde Marx. La idea de equivalencia que conlleva la democracia responde a la equivalencia del individualismo liberal. Aceptar una inconmensurabilidad de cada uno que, sin embargo, tenga que conjugarse en un ser-con que no reproduzca una inequivalencia económica y social.

Esto conlleva, la imposibilidad de figurar la democracia, es decir, la imposibilidad de ser representada como un todo o concepto cerrado. Por su propia esencia la democracia ha de ser abierta, para dar cabida a las singularidades que en su seno puedan ser plurales, unos con otros.

Para terminar, y resaltando el carácter estético de esta línea de pensamiento de Nancy, aportamos una cita en la que se muestra cómo el arte, responde o reacciona a esta condición de la democracia:

La democracia no es figurable. Más aún: no es, por esencia, figural. Tal vez ese el único sentido que, para terminar, pueda dársele: ella depone la asunción de figuración de un destino, de una verdad de lo común. Pero impone configurar el espacio común de toda la riqueza posible de las formas que lo infinito es capaz de adoptar, de las figuras de nuestras afirmaciones y de las declaraciones de nuestros deseos.

Lo que pasa en el arte desde hace cincuenta años muestra de modo elocuente hasta qué punto es real esta exigencia. Así como la ciudad democrática renuncia a figurarse, abandona sus símbolos y sus íconos de manera acaso riesgosa, así ve surgir, en cambio, todas las aspiraciones posibles a formas inéditas. El arte se retuerce en el esfuerzo por dar a luz formas que él mismo querría ver excedidas con respecto a todas las formas de lo que se llama "arte" y a la forma o la idea misma de "arte". (Nancy, 2009).

\section{Conclusiones}

Comprendida desde una ontología relacional del ser-con la democracia alcanza un estatuto distinto al que normalmente se le da. Más allá de situarse como un mero régimen político entre otros, más allá de las expectativas que han sido puestas en ella, la democracia se sitúa a medio camino entre ser un ideal inalcanzable y ser simplemente una forma de estar juntos. La democracia se encuentra así, por decirlo poéticamente, entre el cielo y la tierra, entre el idealismo más puro y el empirismo más basto. Esta es la operación que realiza Jean-Luc Nancy, situar a la democracia en el lugar que le corresponde, rastreando su "verdad" y despojándola así de loq eu algunos han pretendido hacer con ella.

Esto no implica, sin embargo, un ensalzamiento ciego de la democracia, sino un reconocimiento en ocasiones crudo de sus límites y de su dificultad.

Para terminar, cabe resaltar que la ontología del ser-con es eminantemente estética, en el sentido de que el contacto y la relación de los unos con los otros, hasta el extremos de hablar de singularidades plurales, son la base de esta ontología. El contacto, palabra en la que habita también la partícula "con", surge así como el núcleo ontológico del pensamiento de Nancy, haciendo así, de la idea de democracia, una manera de estar en contacto, de poder vivir juntos sin que eso elimine las singularidades de cada uno y sin que ese contacto sea perjudicial, aunque, bien es cierto, el autor no deja de reconocer 
la presencia inevitable del contagio, es decir, la posibilidad imperante de que el contacto se vuelva en nuestra contra. Esta incertidumbre es también una de las característas de ese "estar-con" en elque consiste la democracia, de ahí la conciencia de sus límites y sus fallas.

Retomando el título de la este escrito, podemos decir que el sentido de la democracia no se corresponde con una definición cerrada y acabada, sino, precisamente, es aquello que emerge en la relación de unos con otros cuando hay espacio para la alteridad y la heterogeneidad, cuando la política consiste en hacer espacio para la circulación del sentido antes que en la delimitación de espacios cerrados.

\section{Referencias}

NANCY, J-L. (2006). Ser singular plural, Madrid: Arena Libros.

NANCY, J-L. (2001). La comunidad desobrada, Madrid: Arena Libros.

NANCY, J-L., BAILlY, J-C. (2014). La comparecencia, Madrid: Avarigani.

NANCY, J-L. (2010). Corpus, Madrid: Arena Libros

NANCY, J-L. (2009). La verdad de la democracia, Buenos Aires: Amorrortu

NANCY, J-L. (2011). “Ser-con y democracia” en Revista Pléyade, vol. IV, número 1, ISSN: 0718-655X

Ramperez, F., LeVeque, J-C., Masso Castilla, J. (2014), Márgenes de Jean-Luc Nancy, Madrid: Arena Libros 